\title{
Análise de Ementas de Disciplinas de Avaliação Psicológica: Novos Tempos, Velhas Questões
}

\author{
Rodolfo A. M. Ambiel, Ana Carolina Zuanazzi \\ Catarina Possenti Sette, Ariela Raissa Lima Costa, Felipe Augusto Cunha \\ Universidade São Francisco, Campinas-SP, Brasil
}

\section{RESUMO}

O objetivo desse estudo foi levantar e analisar ementas sobre ensino de avaliação psicológica dos cursos de Psicologia no Brasil. Para tanto, foram acessadas as ementas disponíveis em sites de instituições de ensino cadastradas pelo MEC. Após seleção das ementas, estas foram divididas em unidades de texto e classificadas com base nas Diretrizes para Ensino de Avaliação Psicológica. Como resultados, foram recuperadas 478 ementas provindas de 133 instituições. A distribuição de disciplinas foi do primeiro ao nono semestre, com ênfase no quarto, quinto e sexto. A carga horária é considerada insuficiente dada a quantidade de assuntos básicos a serem tratados. Também há ênfase no ensino tecnicista de testes em detrimento de disciplinas que visam compreensão mais ampla do processo, como o uso de técnicas de avaliação (entrevista, observação, entre outros), elaboração de laudos e psicometria. Muito ainda deve ser modificado para atingir a qualidade mínima na área.

Palavras-chave: formação do psicólogo; ensino superior; testes psicológicos; psicologia; universidades.

\section{ABSTRACT - Analysis of Psychological Assessments Disciplines Syllabus: New Times, Old Issues}

The aim of this study was to retrieve and analyze the syllabuses of psychological assessment disciplines of Psychology courses in Brazil. For this, the discipline syllabuses available on the websites of educational institutions registered by the MEC were accessed. After selecting the discipline syllabuses, they were divided into units of text and classified based on the Guidelines for Teaching Psychological Evaluation. A total of 478 discipline syllabuses of 133 institutions were retrieved. The disciplines were distributed from the first to the ninth semester, with emphasis on the fourth, fifth and sixth semesters. The workload was considered insufficient given the amount of basic issues to be addressed. There was also emphasis on the teaching of test techniques to the detriment of disciplines directed toward a broader understanding of the process, such as the use of other assessment techniques (interviews and observation, among others), report writing and psychometrics. Much still needs to be modified to achieve the minimum quality in the area.

Keywords: psychology education; higher education; psychological testing; psychology; universities.

RESUMEN - Análisis de Planes de Estudios de Evaluación Psicológica: Nuevos Tiempos, Viejas Cuestiones

El objetivo de esta investigación fue recopilar y analizar planes de estudios relacionados con la enseñanza de evaluación psicológica de los cursos de Psicología en Brasil. Razón por la cual se accedió a los planes de estudios disponibles en los sitios web de instituciones de enseñanza registradas por el Ministerio de Educación de Brasil (MEC). Tras seleccionar los planes de estudios, dichos planes fueron divididos en unidades del texto y clasificados con base en las Directrices para Enseñanza de Evaluación Psicológica. Como resultados, se recuperaron 478 planes de estudios provenientes de 133 instituciones. La distribución de las asignaturas fue del primer al noveno semestre, con énfasis en el cuarto, quinto y sexto semestres. La carga horaria fue considerada insuficiente dada la cantidad de asuntos básicos a tratar. También cabe señalar que hay un énfasis en la enseñanza tecnicista de pruebas en detrimento de asignaturas que buscan comprensión más amplia del proceso, como el uso de técnicas de evaluación (entrevista, observación, entre otros), elaboración de informes y psicometría. En definitiva, se necesita numerosas modificaciones para alcanzar la calidad mínima en el área.

Palabras clave: formación del psicólogo; enseñanza superior; testes psicológicos; psicología; universidades.

A avaliação psicológica é uma prática restrita aos psicólogos brasileiros (Brasil, 1962), assumindo um papel fundamental uma vez que é um procedimento inserido em todas as áreas de atuação desse profissional. Ela se constitui como um processo de avaliação global ou específica de um aspecto da pessoa (emocional, comportamental, cognitivo e social) com a finalidade de conhecer seu funcionamento psicológico e, caso necessário, sugerir uma intervenção ou encaminhamento. Para a realização desse processo, pode-se fazer uso 
de uma variedade de recursos, dentre eles entrevistas, observações e aplicação de testes psicológicos (CFP, Conselho Federal de Psicologia, 2003a, 2003b; Löhr, 2011; Urbina, 2007).

Embora seja uma atividade primordial na atuação do psicólogo, a avaliação psicológica é motivo de conflitos e críticas. Segundo Noronha et al. (2002), há autores que enfatizam haver duas visões principais sobre a prática. Por um lado, estão os que defendem a extinção da avaliação psicológica, com foco específico para os testes, argumentando que são reducionistas e promovem uma visão limitada sobre o homem e a sociedade, o que favorece a exclusão social. Do outro lado, estão os pesquisadores que defendem uma avaliação psicológica baseada em evidências empíricas, ressaltando que o maior problema está na forma como os instrumentos são utilizados. Assim, é necessário o aprimoramento do ensino e formação dos psicólogos para que se apropriem do processo da avaliação (Borsa, 2016; Mendes, Nakano, Silva, \& Sampaio, 2013; Noronha et al., 2002; Rafalski \& Andrade, 2015).

Considerando a história da prática de ensino da avaliação psicológica, é possível verificar o déficit encontrado na formação dos profissionais de Psicologia (Bandeira, 2011). Inicialmente, essa temática era pouco estudada e quase nunca contemplada em cursos de graduação. Na década de 1990, algumas entidades como o Instituto Brasileiro de Avaliação Psicológica (IBAP), a Associação Nacional de Pesquisa e Pós-Graduação em Psicologia (ANPEPP), a Associação Brasileira de Rorschach e Outras Técnicas Projetivas (ASBRo) e o próprio Conselho Federal de Psicologia (CFP) adotaram medidas de conscientização e divulgação da importância desse campo de atuação, a fim de modificar o cenário nacional (Conselho Federal de Psicologia, 2010). Como exemplo, a publicação de cartilhas para promoção de reflexões sobre o assunto (CFP, Conselho Federal de Psicologia, 2013) e o desenvolvimento de diretrizes (Nunes et al., 2012).

Essas diretrizes, desenvolvidas pelo IBAP (Nunes et al., 2012) com respaldo em resoluções do Conselho Federal de Psicologia e Código de Ética Profissional do psicólogo e baseado em referências da área, englobam 27 habilidades mínimas para serem desenvolvidas pelos estudantes ao longo de sua formação básica. Há ainda uma proposta de seis disciplinas e seus respectivos conteúdos essenciais, servindo como um guia para cursos de Psicologia (Nunes et al., 2012), elas foram chamadas de Avaliação Psicológica I, II, II, IV, V e Estágio supervisionado em avaliação psicológica que consideram também a proposta de Noronha et al. (2002). A primeira disciplina se dedica ao ensino de aspectos históricos, legislação, ética e psicometria. A segunda se refere sobre a avaliação cognitiva enquanto que a terceira e quarta tratam, respectivamente, sobre técnicas de autorrelato e projetivas para avaliação afetiva e comportamental. A quinta aborda o uso e limitação de técnicas de rapport, observação e entrevista, além do planejamento da avaliação levando em conta o contexto do sujeito. A última propõe a prática em avaliação psicológica, desde a primeira entrevista, planejamento, aplicação de testes até a redação de documentos e comunicação de resultados (Nunes et al., 2012).

Embora se observe o avanço desde a década de 1990 em termos de melhoria do ensino (Bandeira, 2011), alguns estudos ainda indicaram falhas no campo da formação em avaliação psicológica. Em relação a percepção dos alunos sobre conteúdos relacionados à avaliação psicológica, Paula, Pereira e Nascimento (2007) verificaram que estudantes de Psicologia relataram serem insuficientes as competências ensinadas para a prática da avaliação no âmbito do profissional da Psicologia nos diferentes contextos. Aliado a isso, Noronha, Nunes e Ambiel (2007) salientaram que, embora os psicólogos em formação tenham considerado relevante o ensino de ética na avaliação psicológica, disciplinas, como estatística, psicometria e construção de instrumentos, foram avaliadas como de menor importância, apesar de serem base para compreensão aprofundada do tema.

Para avaliar a perspectiva dos docentes, Noronha, Castro, Ottati, Barros e Santana (2013) analisaram conteúdos mais frequentemente ministrados por professores de graduação. Eles encontraram que a maioria relatou ensinar técnicas de avaliação, como aplicação de testes em detrimento do ensino sobre elaboração de documentos e histórico da avaliação. Resultados semelhantes foram encontrados por Bardagi, Teixeira, Segabinazi, Schelini e Nascimento (2015), indicando maior predominância do ensino de correção e interpretação de testes específicos e menor ocorrência de atividades de elaboração de documentos e construção de instrumentos, bem como ensino de como verificar a qualidade de um teste.

A falha na formação também foi dada como uma das justificativas para profissionais não utilizarem avaliação psicológica em suas rotinas profissionais (Hazboun \& Alchieri, 2013). Por sua vez, os psicólogos que relataram realizar avaliação com frequência, indicaram, dentre outros pontos, a falta de cursos de capacitação como uma importante dificuldade enfrentada (Hazboun \& Alchieri, 2014). Tudo isso sinaliza a necessidade de reformulação da formação básica em Psicologia, sendo fundamental uma sistematização e coerência do ensino nas diversas instituições que ofertam o curso de Psicologia (Conselho Federal de Psicologia, 2013; Noronha, Carvalho, Miguel, Souza, \& Santos, 2010).

O ensino de avaliação psicológica na graduação é preconizado como um eixo estruturante pelas Diretrizes Curriculares Nacionais recentemente revisada pelo Conselho Federal de Psicologia (CFP, 2018a). Esse documento indica conhecimentos específicos que devem ser contemplados pelos cursos, dentre eles "avaliar fenômenos humanos de ordem cognitiva, comportamental, afetiva, perceptiva, comunicacional, cultural e social, em diferentes contextos de sua atuação" e "elaborar registros 
elaborar registros documentais decorrentes da prestação de serviços psicológicos, tais como pareceres técnicos, laudos, relatórios e evolução em prontuários, de acordo com os preceitos é cos e legais" (Art. 9).

Nessa perspectiva de sistematização e levantamento de competências básicas na formação, Noronha et al. (2002) propuseram quatro conteúdos, focados na avaliação psicológica que deveriam ser trabalhados em disciplinas da Psicologia. A saber, teoria da medida e psicometria, avaliação da inteligência, avaliação da personalidade (incluindo as técnicas projetivas) e planejamento, execução e redação de resultados da avaliação psicológica. Observa-se que, para compreensão desses conteúdos, diferentes competências e conhecimentos estariam envolvidos, tais como a noção histórica sobre a avaliação psicológica, princípios éticos, uso da avaliação em diferentes contextos, entre outros.

Com o objetivo de verificar os conteúdos e disciplinas relacionadas à avaliação psicológica em cursos de formação em Psicologia, Noronha (2006) analisou 41 ementas de disciplinas relacionadas à avaliação psicológica de 38 universidades das cinco regiões do Brasil. Foram elaboradas 11 categorias para classificação dos conteúdos apresentados nas ementas: teoria psicológica, testes de personalidade e inteligência, aplicação de testes, psicometria, elaboração de laudos, ética na avaliação, fundamentos da avaliação psicológica, técnicas projetivas, psicodiagnóstico e outros testes. A autora concluiu a necessidade de mais investimentos, tanto do corpo docente quanto de pesquisadores, para melhoria da qualidade do que tem sido ensinado, explorando muito mais um pensamento reflexivo do que técnico de aplicação de testes. Aliado a isso, as cargas horárias dedicadas às disciplinas de avaliação psicológica variaram muito, sendo a média considerada insatisfatória $(M=226,61, D P=108,359)$.

O estudo de Castro (2013) teve como objetivo analisar e caracterizar o ensino de avalição psicológica somente do estado de São Paulo a partir de uma análise documental. As informações necessárias foram provindas de diferentes tipos de documentos de 73 instituições, como matrizes curriculares e planos de ensinos das disciplinas de avaliação psicológica, disponibilizadas nos sites ou enviadas por e-mail pelos responsáveis das universidades. Dentre os resultados mais relevantes, foi observado que a maior parte das instituições de ensino é de domínio privado $(82,1 \% ; N=55)$; e as disciplinas com foco em avaliação psicológica são nomeadas com mais frequência como Técnicas de Exame Psicológico $(31,3 \% ; N=21)$ e Avaliação Psicológica $(29,8 \% ; N=20)$. As disciplinas foram mais distribuídas entre o $4^{\circ}$ e o $7^{\circ}$ semestres, com maior ênfase nos $5^{\circ}$ e $6^{\circ}$ semestres; possuindo carga horária de aproximadamente de 71 a 80 horas. Os achados vão ao encontro dos estudos realizados anteriormente, demonstrando que o ensino em avaliação psicológica ainda apresenta falhas, o que acaba refletindo na atuação do profissional.
Em um estudo recente, Freires, Silva Filho, Monteiro, Loureto e Gouveia (2017) analisaram ementas de cursos de graduação em Psicologia da região Norte. Das 56 ementas selecionadas, os autores verificaram variedade de nomenclatura das disciplinas, sendo a mais frequentes "Psicodiagnóstico" (19\%) e "Técnicas de Avaliação Psicológica" (10\%). A carga horária média foi de 240 horas $(D P=11,20)$ com a primeira disciplina de avaliação sendo apresentada no segundo ano de graduação $\left(3^{\circ}\right.$ e $4^{\circ}$ semestre). Os autores concluem, assim como nos estudos aqui já relatados, o não atendimento das recomendações propostas por Nunes et al. (2012); além de maior enfoque no processo psicodiagnóstico e no contexto clínico.

Essas publicações são representativas de um movimento na área de avaliação psicológica no sentido de organizar e aprimorar o conhecimento e capacidade crítica dos psicólogos. Dessa forma, com essas pesquisas e diretrizes, busca-se instrumentalizar cursos de formação e prezar pela qualidade dos serviços prestados, motivando um trabalho mais reflexivo e menos mecânico. Como mencionado há mais de uma década por Noronha (2006), muito ainda precisa ser desenvolvido para que se atinja o mínimo esperado nessa área. A questão que se levanta é, passado todo esse tempo, o que se tem de novo no quesito investimento na formação básica dos psicólogos? Houve alguma melhoria no ensino de avaliação psicológica, em termos nacionais, após a publicação do texto com diretrizes? O que ainda precisa ser trabalhado?

Pensando nessas questões norteadoras e tendo em vista a problemática e metodologia levantadas por Noronha (2006) sobre a qualidade de cursos de graduação, o objetivo deste estudo foi realizar um levantamento e analisar as ementas dos cursos de Psicologia do país voltadas para o ensino de avalição psicológica, tomando como base o artigo com as Diretrizes para Ensino de Avaliação Psicológica (Nunes et al., 2012).

\section{Método}

\section{Critérios e procedimentos de busca das ementas}

Foram analisadas ementas de cursos de graduação em Psicologia de instituições brasileiras públicas e particulares. Para tanto, foi realizada uma busca em outubro/2017 no site do Ministério da Educação (MEC; http://emec.mec.gov.br/) para levantamento dos cursos de graduação em Psicologia ativos de instituições cadastradas, considerando-se as cinco regiões do país. Em seguida, foi verificado, no site de cada instituição cadastrada, se as ementas de disciplinas com conteúdo sobre avaliação psicológica estavam disponíveis para acesso público. Importante ressaltar que as disciplinas e ementas foram investigadas por instituições, e não nos cursos de Psicologia cadastrados do MEC, uma vez que uma mesma instituição pode ter mais de um campus e, 
por isso, dois ou mais cursos disponíveis para acesso no site. Caso a ementa da disciplina não estivesse disponível, um e-mail era enviado ao coordenador do curso da respectiva instituição explicando os objetivos dessa pesquisa e solicitando o envio das ementas vigentes.

Como critério de seleção das disciplinas, foram levantadas palavras-alvo que poderiam estar presentes no título delas, selecionadas com base nas diretrizes do IBAP. As palavras elencadas foram: "avaliação cognitiva", "avaliação de desempenho", "avaliação da inteligência", "avaliação neuropsicológica", "avaliação da personalidade", "avaliação/técnica projetiva", "avaliação psicológica", "entrevista”, "diagnóstico", "estágio", "ética”, "exames”, "medidas", "observação", "psicodiagnóstico", "psicometria", "técnicas de avaliação", "técnicas de exame", "documentos e elaboração de documentos", "testagem e teste", "triagem" e "instrumentos". Para estágios e/ou disciplinas práticas, foi realizada a busca das palavras-alvo na própria ementa, uma vez que, em muitos casos, o nome da disciplina é apenas Estágio, sem maiores especificações. A seleção resultou em 478 ementas dentre as disponibilizadas por e-mail e no site da instituição, como será detalhado no tópico Resultados.

\section{Procedimentos de análise das ementas}

As ementas selecionadas foram organizadas em uma planilha eletrônica com informações sobre a carga horária, semestre em que era ministrada, categoria administrativa da instituição (pública ou particular), região, título da disciplina, conteúdo da ementa e as unidades de análise. Com a planilha finalizada, foram selecionadas aleatoriamente, por meio de sorteio eletrônico, $25 \%$ das ementas do conjunto final para a próxima etapa do estudo (ver sessão Resultados). A opção por utilizar essa porcentagem para análise foi devido ao grande número de ementas que tornariam a análise do corpus total inviável. Associado a isso, foi feita análise para verificar se o recorte foi representativo da amostra final. Essas ementas selecionadas foram divididas em unidades de texto, conforme os preceitos de Bardin (1977) para que o conteúdo fosse explorado como unidades de análise. Análises descritivas foram realizadas, como frequências de instituições por região, particulares e públicas, semestres e carga horária.

Posteriormente, de maneira independente, os autores agruparam as 27 competências para o ensino de avaliação psicológica propostas pelo IBAP (Nunes et al., 2012) em categorias, de acordo com a similaridade dos conteúdos, visando trabalhar com uma quantidade menor de variáveis. Na sequência, os agrupamentos foram comparados chegando-se a um consenso acerca das categorias. O conjunto final ficou composto por oito categorias amplas, apresentadas na Tabela 1.

Posteriormente, cinco ementas foram selecionadas aleatoriamente para que cada um dos cinco avaliadores analisasse, separasse em unidades de texto e categorizasse nas competências, segundo apresentado na Tabela 1. Foi realizado o consenso da categorização dessas ementas pelos autores, para que possíveis divergências fossem esclarecidas e para afinar os procedimentos dessa etapa. Finalizado o alinhamento do procedimento, o conjunto de $25 \%$ (125) das ementas foi divido entre os avaliadores para categorização (25 ementas para cada).

Tabela 1

Agrupamento das Competências Baseadas em Nunes et al. (2012)

\begin{tabular}{ll}
\hline \multicolumn{1}{c}{ Categorias Propostas } & \multicolumn{1}{c}{ Competências - IBAP } \\
\hline 1. Histórico & (1) Histórico da avaliação psicológica (nacional e internacional). \\
2. Ética e Legislação & (2) Legislação pertinente à avaliação psicológica; \\
& (3) Aspectos éticos na realização da avaliação psicológica; \\
& (10) Crítica às consequências sociais da avaliação psicológica. \\
3. Fundamentos & (6) Funções, origem, natureza e uso dos testes; \\
de Psicometria & (7) Processo de construção de instrumentos psicológicos; \\
& (8) Validade, precisão, normatização e padronização de testes. \\
4. Testes Psicológicos & (9) Uso adequado de tabelas normativas dos manuais de testes; \\
& $\begin{array}{l}\text { (13) Administrar, corrigir, interpretar e redigir os resultados de testes/técnicas; } \\
\text { (14) Selecionar instrumentos/técnicas a partir de objetivos, público alvo e contexto. }\end{array}$ \\
$\begin{array}{l}\text { 5. Aspectos Teóricos } \\
\text { de Técnicas/ }\end{array}$ & $\begin{array}{l}\text { (12) Conhecimento sobre fundamentação teórica de testes psicométricos e do } \\
\text { fenômeno avaliado; }\end{array}$ \\
\hline
\end{tabular}


Tabela 1 (continuação)

Agrupamento das Competências Baseadas em Nunes et al. (2012)

Categorias Propostas Competências - IBAP

6. Avaliação Psicológica (4) Analisar/estabelecer condições de espaço físico adequadas;

(Processo, Objetivo, (5) Compreender a avaliação psicológica enquanto processo; Prática)

(11) Avaliar fenômenos humanos de ordem cognitiva, afetiva e comportamental em diferentes contextos;

(16) Planejar uma avaliação de acordo com objetivo, público alvo e contexto;

(17) Planejar processos avaliativos e agir de forma coerente com os referenciais teóricos adotados;

(18) Identificar e conhecer peculiaridades de diferentes contextos de aplicação da avaliação psicológica;

(22) Identificar/Analisar as possibilidades de uso e limitações de diferentes técnicas de avaliação psicológica.

7. Outras Técnicas de Avaliação Psicológica

(19) Saber estabelecer rapport no momento da avaliação;

(20) Conhecer teorias sobre entrevista psicológica;

(21) Conhecer teorias sobre observação do comportamento.

8. Devolutiva, Encaminhamento

(23) Comparar/Integrar informações de diferentes fontes; e Documentos

(24) Fundamentar teoricamente os resultados;

(25) Elaborar laudos e documentos psicológicos, bem como ajustar sua linguagem e conteúdo de acordo com contexto;

(26) Comunicar resultados por meio de devolutiva verbal;

(27) Realizar encaminhamento/intervenção a partir de resultados.

Nota. Na coluna "Competências-IBAP" estão entre parênteses os números correspondentes as competências elencadas por Nunes et al. (2012)

\section{Resultados}

Com base no objetivo proposto para este estudo, os resultados foram distribuídos em dois principais pontos. Primeiro foram realizadas análises descritivas e, posteriormente, analisou-se os conteúdos das ementas e as unidades de texto nas categorias desenvolvidas pelos autores a partir das competências descritas pelo IBAP. Na Tabela 2, são apresentadas as informações referentes ao número de cursos, instituições, disciplinas e ementas.

Tabela 2

Análise Descritiva dos Resultados

\begin{tabular}{|c|c|c|c|}
\hline Região & Cursos cadastrados & $\begin{array}{l}\mathrm{N}^{\circ} \text { de instituições com } \\
\text { ementas disponíveis }\end{array}$ & $\begin{array}{c}\mathrm{N}^{\circ} \text { de ementas } \\
\text { selecionadas }\end{array}$ \\
\hline Norte & 174 & 27 & 68 \\
\hline Nordeste & 41 & 13 & 116 \\
\hline Centro-Oeste & 76 & 13 & 60 \\
\hline Sudeste & 342 & 31 & 146 \\
\hline Sul & 157 & 49 & 88 \\
\hline Total & 790 & 133 & 478 \\
\hline
\end{tabular}

Como é possível verificar na Tabela 2, há 790 cursos de graduação cadastrados no site do MEC, sendo o Sudeste a região com maior número de cursos cadastrados, seguido pelo Norte, ficando o Nordeste com a menor quantidade de cursos. Os 790 cursos estão distribuídos entre, aproximadamente, 621 instituições. Do total de 133 instituições, 122 disponibilizavam as ementas nos sites e o restante $(9 \%)$ foram encaminhadas por $e$-mail, via solicitação por parte dos pesquisadores, finalizando em 478 ementas. Em relação ao número de instituições com ementas disponíveis, o Sul, Sudeste e Norte apresentaram os maiores números. Referente ao número de disciplinas acessadas, o Sudeste, seguido pelo Norte foram as regiões que mais foi possível acessar as ementas.

No que se refere ao momento das disciplinas no decorrer do curso, elas variaram entre primeiro e nono 
semestre. O período com maior frequência de disciplinas foi o quinto semestre $(n=102 ; 18,9 \%)$, seguido pelo sexto $(n=92 ; 17 \%)$ e quarto $(n=83 ; 15,4 \%)$. Além disso, verificou-se que $37,4 \%$ das disciplinas estão sendo ofertadas entre o primeiro e quarto semestre e $56,3 \%$ até o quinto semestre, isto é, no início e até a metade do curso. Em relação à carga horária, as disciplinas acessadas variaram entre 30 e 240 horas $(M=64,32 ; D P=24,0)$; as mais frequentes foram 60 horas $(n=184 ; 34,1 \%), 80$ horas $(n=86 ; 15,9 \%)$ e 40 horas $(n=38 ; 7 \%)$. Observou-se média de quatro disciplinas por curso, com carga horária variando entre 36 e 840 horas, com média de 269,70 horas $(D P=144,202)$.

As 478 disciplinas foram separadas com base no nome e conteúdo, por exclusivamente teórica $(n=301)$, prática (estágios; $n=113$ ) e ética $(n=64)$, para tanto todo o material foi lido na íntegra e discutido pelos autores. Em relação à distribuição das disciplinas ao longo do curso e de acordo com o conteúdo, tem-se disciplinas teóricas do 1 o ao 90 semestre, com maior frequência nos 4 o, $(n=63) 5$ o $(n=73)$ e 6o $(n=55)$ semestres. As disciplinas que apresentaram conteúdo de caráter prático estiveram presentes do $1 \mathrm{o}$ ao $10 \mathrm{o}$ semestre, com aumento de frequência a partir do 50 semestre e redução no 80 semestre. Por fim, as disciplinas de ética ocorrem do 1 o ao 90 semestre, concentrando-se majoritariamente entre o 2 o $(n=14), 3$ o $(n=17)$ e 5 o $(n=10)$ semestres. Em relação à média de carga horária de acordo com o conteúdo, observou-se maior carga para disciplinas práticas $(M=73 \mathrm{~h})$, seguida das exclusivamente teóricas $(M=64 \mathrm{~h})$ e ética $(M=52 \mathrm{~h})$.

Posterior às análises descritivas, foi realizada a verificação dos conteúdos das ementas selecionadas. As ementas foram separadas em unidades de análise e categorizadas de acordo com os agrupamentos mencionados na Tabela 1. Não houve limite de categorias possíveis por ementa, inclusive podendo ser repetida caso duas unidades de análise complementassem aspectos diferentes de uma mesma categoria. É importante ressaltar que, do conjunto final de ementas, 125 (25\% do total) foram utilizadas para esta análise. Objetivou-se com esse procedimento, atingir um número representativo da amostra geral.

Foi feita a frequência e porcentagem de ementas selecionadas por região para verificar se a seleção aleatória correspondeu à distribuição total encontrada. Verificouse que 20 ementas eram do Norte (29\%), 32 do Nordeste (28\%), 14 do Centro-Oeste (23\%), 32 do Sudeste (22\%) e 27 eram da região Sul (31\%). Os dados indicam representatividade da parcela selecionada para análise.

A Tabela 3 apresenta os resultados referentes à categorização de cada ementa a partir das unidades de análise. Dessa forma, é possível analisar quais conteúdos estão sendo mais frequentemente ministrados no que tange o ensino de avaliação psicológica nas cinco regiões do Brasil.

Tabela 3

Frequência das Categorias nas Unidades de Análise das Ementas

\begin{tabular}{lcc}
\hline \multicolumn{1}{c}{ Categoria } & Frequência & Porcentagem \\
\hline NC & 83 & 9,80 \\
& 23 & 2,70 \\
1. Histórico & 119 & 14,10 \\
2. Ética e Legislação & 78 & 9,20 \\
3. Fundamentos de Psicometria & 143 & 16,90 \\
4. Testes Psicológicos & 106 & 12,50 \\
5. Aspectos Teóricos de Técnicas/Construtos Avaliados & 146 & 17,30 \\
6. Avaliação Psicológica (Processo, Objetivo, Prática) & 82 & 9,70 \\
7. Outras Técnicas de Avaliação Psicológica & 66 & 7,80 \\
8. Devolutiva, Encaminhamento e Documentos & 846 & 100,00 \\
Total & & \\
\hline
\end{tabular}

Nota. NC=Nenhuma Categoria. NC corresponde às unidades de texto que não correspondiam a nenhuma categoria baseadas em Nunes et al. (2012)

Como pode ser observado na Tabela 3, 846 unidades de análise foram extraídas das ementas e categorizadas de acordo com as competências para avaliação psicológica. A categoria mais frequente foi Avaliação Psicológica (processo, objetivo, prática), compreendendo conteúdos relacionados a processo, avaliação dos fenômenos humanos, planejamento adequado da avaliação, além do conhecimento dos diferentes contextos, possibilidades e limitações das técnicas usadas na avaliação psicológica. A segunda categoria de conteúdos mais frequentes foi Testes Psicológicos, incluindo o uso adequado dos manuais e dos testes e técnicas, além da seleção dos instrumentos; seguida pela categoria Ética e Legislação, referente a conteúdos relacionados à legislação e aspectos 
éticos na avaliação psicológica, assim como consequências sociais. Em relação à categoria de Ética e Legislação, vale reforçar que foram selecionadas ementas que tratassem da intersecção da ética relacionada a aspectos da avaliação psicológica.

As quatro categorias menos frequentes trabalhadas em disciplinas voltadas para formação nessa área foram, em ordem decrescente, Outras Técnicas de Avaliação Psicológica (referente ao conhecimento sobre estabelecimento de rapport, teorias sobre entrevista psicológica e observação comportamental), Fundamentos de Psicometria (aborda conteúdos relativos às funções, natureza e processo de construção dos testes além de elementos básicos da psicometria como validade, precisão e normatização), Devolutiva, Encaminhamento e Documentos (composto por ensino de integração de diferentes fontes e uso de teorias para fundamentar os resultados por meio de escrita de laudos/documentos psicológicos, além dos encaminhamentos) e Histórico (relacionado ao conteúdo histórico da avaliação psicológica em âmbito nacional e internacional). Somando a porcentagem de vezes que cada uma dessas categorias apareceu, observa-se que esses conteúdos são contemplados apenas em $29 \%$ das vezes, apesar de ser correspondente à metade das categorias propostas (quatro de oito categorias). Isso implica no fato de que essas categorias não estão sendo lecionadas ou quando o estão, é de maneira pouco aparente. Por fim, 83 unidades de análise foram classificadas como NC. Nessa categoria, foram incluídos conteúdos que não eram claramente ou diretamente relacionados a qualquer um dos grupos listados anteriormente, como, por exemplo, teorias sobre personalidade, cognição, estresse, emoções, valores morais, psicoterapia, bioética, entre outros.

\section{Discussão}

O objetivo deste estudo foi realizar um levantamento e analisar ementas relacionadas à avaliação psicológica de cursos de graduação em Psicologia, no âmbito nacional. As ementas foram inicialmente analisadas em relação à quantidade disponível por região e por instituição, sendo que as regiões Sudeste, Sul e Norte apresentaram valores mais expressivos, sendo posteriormente analisadas em termos de conteúdos e categorias. Percebe-se que a formação atual ainda se distancia da proposta de Nunes et al. (2012). Ainda que se tenha avançado em com algumas disciplinas, em outras, observa-se a predominância de uma abordagem tecnicista e pouco reflexiva.

No que se refere aos dados descritivos, observou-se distribuição relativamente proporcional entre o número de cursos ofertados e o tamanho das regiões em termos de população. Dessa forma, o Sudeste, concentrou aproximadamente $43 \%$ de todos os cursos cadastrados pelo MEC. Os dados demográficos indicam que essa região também abarcou o maior número de habitantes, concentrando aproximadamente $42 \%$ da população brasileira.
As regiões Norte e Sul, são habitadas por aproximadamente $8 \%$ e $14 \%$ da população brasileira, respectivamente (IBGE, 2017). Embora a região Sul seja mais povoada, apresentou menor frequência de cursos que a Norte. Vale ressaltar que não foram analisados os números de vagas ofertadas por curso, dado que poderia contribuir para explicação desse fato tendo em vista que a quantidade de vagas e número de cursos são aspectos complementares para se compreender a distribuição regional.

No presente estudo e nas pesquisas de Freires et al. (2017) e Castro (2013), também não foi possível o acesso ao conteúdo de todas as disciplinas. Porém, no caso dos estudos citados, respectivamente, $22 \%$ e $30,4 \%$ das instituições não disponibilizavam informações, enquanto aqui $88 \%$ não apresentavam conteúdo referente às ementas. Ambas as pesquisas citadas, adotaram metodologia diferente da aqui empregada, uma vez que consideraram as matrizes curriculares e ementas. Em algumas instituições, verificou-se a disponibilização da matriz, que apresentava apenas os nomes das disciplinas, mas não das ementas, o que explicaria a divergência, uma vez que, para este estudo, foram consideradas apenas as ementas.

Em relação à distribuição das disciplinas, observou-se maior prevalência no $5^{\circ}, 6^{\circ}$ e $4 \mathrm{o}$, em ordem decrescente; esses resultados vão ao encontro do estudo de Castro (2013), que também mostrou uma frequência maior nesses semestres. No estudo de Noronha (2006) a concentração das disciplinas foi no $3^{\circ}$ semestre. Isso indica que as disciplinas relacionadas à avaliação psicológica estão sendo ministradas após os dois primeiros anos de curso, com exceção das disciplinas de Ética que aparecem já no início do curso. Vale ressaltar que as disciplinas de ética foram consideradas devido aos processos éticos em relação à avaliação psicológica e por ser conteúdo adotado nas diretrizes de Nunes et al. (2012). Essa distribuição das disciplinas pode ser considerada uma vantagem visto que o aluno está mais apto a compreender a complexidade do processo de se avaliar uma pessoa. O resultado indica uma maior atenção com a preparação profissional, uma vez que se espera que a partir do meio do curso o estudante já tenha adquirido conteúdos teóricos suficientes para iniciar a prática.

No que diz respeito à média de disciplinas, voltadas para avaliação psicológica, foi de quatro por curso, e a carga horária variando entre 36 e 840 horas. Os resultados de Freires et al. (2017) e Noronha (2006) são similares aos encontrados neste estudo, analisados por ambos autores como insuficientes. Bandeira (2011) demonstrou haver falha no ensino e formação em avaliação psicológica, devido à falta de conteúdos importantes para o processo. Compreende-se que dada as diretrizes e as 27 competências elaboradas por Nunes et al. (2012), a média de disciplinas, bem como a carga horária, ainda não se mostram suficientes para abarcar minimamente todo o conteúdo necessário para o ensino da avaliação psicológica. Nesse sentido, após 11 anos da publicação de 
Noronha (2006) avaliando as ementas em avaliação psicológica e cinco anos das diretrizes propostas por Nunes et al. (2012), pode-se verificar que não houve mudanças significativas em termos de quantidade de disciplinas dedicadas à essa área.

$\mathrm{Na}$ categorização das unidades de texto, verificou-se que a categoria 6 , referente ao processo, objetivo e prática em avaliação psicológica foi mais frequente nas ementas. Hipotetiza-se que essa ocorrência está relacionada a abrangência da categoria e dos elementos que a compõe. Ela reúne sete dos 27 elementos propostos por Nunes et al. (2012), que vão desde estabelecimento do rapport, planejamento de técnicas e instrumentos a serem utilizados, conhecimento de uma variedade de fenômenos psicológicos, adequação da avaliação ao contexto até reconhecimento das limitações da própria avaliação. Tais elementos envolvem uma variedade de temáticas que podem estar relacionadas com disciplinas teóricas ou práticas, inicias ou avançadas e, portanto, explicaria a maior frequência nas ementas.

A segunda categoria mais abordada foi a 4, referente a testes psicológicos. Ela engloba elementos que falam sobre o manuseio de manuais, conhecimentos sobre seleção e administração dos testes específicos. Embora essa categoria indique conceitos sobre o uso dos testes em diferentes contextos, o conteúdo predominante é o ensino da testagem, apenas um dos passos da avaliação psicológica. Em contrapartida, é notável que disciplinas que abordam outras ferramentas utilizadas nesse processo, como as técnicas de observação e diferentes tipos de entrevistas, ainda são preteridas. Associado a isso, questões referentes a devolutiva, escrita de documentos e encaminhamentos, tão frequentemente relacionados a processos éticos (Amendola, 2014; Preto \& Fajardo, 2015; Frizzo, 2004; Lago, Yates, \& Bandeira, 2016; Shine, 2009) são pouco abordadas.

Os resultados demonstraram uma falha na formação de profissionais, em que assuntos relacionados ao histórico, qualidade de instrumentos psicológicos e a forma de configurar os resultados em um relatório ou uma fala que terá repercussões na vida de outro são considerados "tópicos secundários" (Freires et al., 2017, p. 213). A consequência é estudantes que se tornam profissionais pouco preparados para a prática e necessitam de educação continuada que desenvolvam, de maneira minuciosa, todos os passos da avaliação psicológica, desde o planejamento até a devolução.

Resultados semelhantes foram encontrados em outras pesquisas que demonstraram que a maioria dos professores relatou ensinar formas de aplicação, correção e interpretação de testes, em detrimento de outros conteúdos (Bardagi et al., 2015; Noronha et al., 2013). Apesar dos esforços de pesquisadores e entidades visando a melhoria da formação de psicólogos no que se refere à avaliação psicológica, esse resultado é similar aos achados por Noronha (2006), indicando o ensino como tecnicista, muitas vezes restringindo a prática acadêmica apenas à aplicação de instrumentos psicológicos, sugerindo que ainda há muito para mudar em termos de como os testes são ensinados, sem proporcionar um pensamento reflexivo acerca a qualidade e funcionalidade deles.

A terceira categoria mais presente nas ementas foi a 2 , referente às ética e legislação. Ela engloba elementos sobre aspectos éticos e legislações pertinentes à avalição psicológica, como crítica as consequências sociais delas. Apesar de Noronha (2006) não ter considerado esse conteúdo, foi objeto de análise do presente estudo por estar presente nas diretrizes de Nunes et al. (2012). Por meio da análise das ementas, foi possível observar que diversos cursos tinham como nome da disciplina e conteúdo na ementa ética no geral, não focalizando conteúdos éticos do processo de avaliação psicológica, apesar de ser considerada uma discussão relevante por parte de estudantes de graduação (Noronha et al., 2007). Isso é coerente com a pesquisa de Noronha et al. (2007) que sugeriram que as disciplinas envolvendo ética não necessariamente são voltadas para a prática da avaliação. Estudos futuros devem investigar os conteúdos programáticos de tais disciplinas para que se possa compreender quais conteúdos éticos estão sendo ministrados nos cursos de graduação em Psicologia.

Por fim, observou-se que alguns conteúdos de ementas não correspondiam a nenhuma categoria listada (NC). Como exemplificado, esses temas envolviam questões marginais (psicoterapia, bioética, valores morais etc.) ou basais (teorias da personalidade, cognição, estresse etc.) à avaliação psicológica. Hipotetiza-se que esses temas possam ter sido inseridos nas ementas para estabelecer linhas de base para então abordar o conteúdo-alvo dentro da área de avaliação. Em estudos futuros, analisar o conteúdo programático das disciplinas poderia trazer maiores esclarecimentos sobre a questão. De toda forma, chama atenção para conteúdos que ocupam espaço e carga horária das disciplinas voltadas a avaliação, mas que talvez não a estejam abordando. Ressalta-se que, em estudos anteriores, não foram analisados esse tipo específico de ocorrência.

Retomando as questões disparadoras deste artigo, referentes aos investimentos realizados na formação básica de psicólogos e melhorias no ensino de avaliação psicológica após a publicação das diretrizes de Nunes et al. (2012), algumas considerações podem ser realizadas. Ainda são poucos os avanços no que diz respeito aos conteúdos ministrados em disciplinas de avaliação psicológica, sendo o principal aspecto a ser trabalhado o fato de o ensino ser marcadamente tecnicista e pouco reflexivo. Desenvolver competências referentes ao conhecimento sobre as propriedades de testes psicológicos é fundamental para uma compreensão aprofundada dessa ferramenta. Associado a isso, conteúdos relacionados a devolutivas e encaminhamentos, requisitos para a conclusão do processo, devem ser alvo de ensino. 
Algumas limitações foram verificadas no presente estudo. Em primeiro lugar, não foi possível o acesso a ementas de todas as instituições, o que inviabilizou a observação e mapeamento mais próximos da realidade. A maioria dos cursos não disponibilizam as ementas das disciplinas no site da instituição. Foi possível acessar apenas $21,5 \%$ das ementas, sendo que algumas delas só foram disponibilizadas por intermédio de solicitação direta ao coordenador do curso. Esse é um importante ponto a ser discutido, pois implica na não divulgação e restrição de acesso à informação. Essa conduta é compreendida como prejudicial tanto para pesquisadores, como no caso do presente estudo, como também para possíveis alunos que desejassem conhecer mais sobre o que aquelas instituições oferecem. Outra limitação encontrada foi a realização da análise de apenas $25 \%$ das ementas selecionadas, fato ocorrido pela grande quantidade de material que tornaria a análise repetitiva e inviável.

Também deve-se ressaltar que este trabalho não analisou o conteúdo programático dos cursos e considera-se que, em estudos futuros, essa limitação possa ser transposta. Observou-se que o conteúdo apresentado em algumas ementas era demasiadamente amplo, não esclarecendo quais pontos ou categorias realmente eram ministrados na disciplina. Ao menos $9,8 \%$ das unidades de texto não correspondiam a nenhuma das categorias propostas. Essa impossibilidade envolve tanto a mistura de conteúdos não referentes a avaliação psicológica como também a descrição pouco detalhada, o que inviabilizou a compreensão do que era realmente ministrado. Dessa forma, o acesso e análise ao conteúdo programático minimizaria essa questão, favorecendo e enriquecendo futuras análises. Em estudos futuros, sugere-se a análise e comparação por regiões do Brasil, favorecendo a identificação de potencialidades e falhas específicas de cada região, o que contribuiria para trabalhos voltados às necessidades características de cada área.

Esse levantamento pretendeu ser pormenorizado em suas análises, embora possam ser delineados métodos ainda mais aprofundados. Entende-se que iniciativas como a presente pesquisa e as anteriormente citadas são capazes de mobilizar em especial os órgãos responsáveis pela discussão e decisão de medidas relacionadas ao ensino de avaliação psicológica, fornecendo material atualizado e fidedigno que sintetiza e problematiza a situação do ensino de avaliação psicológica. Um grande avanço foi conquistado recentemente com o reconhecimento dela enquanto uma especialidade (CFP, 2018b), indicando ser possível pensar e modificar o atual cenário.

\section{Referências}

Amendola, M. F. (2014). Formação em psicologia, demandas sociais, contemporâneas e ética: Um perspectiva. Psicologia: Ciência E Profissão, 34(4), 971-983. doi:10.1590/1982-370001762013

Bandeira, D. R. (2011). Repensando a formação em avaliação psicológica no Brasil. Em Conselho Federal de Psicologia (Ed.), Ano da avaliação psicológica: Textos geradores (pp. 129-132). Brasília.

Bardagi, M. P., Teixeira, M. A. P., Segabinazi, J. D., Schelini, P. W., \& Nascimento, E. (2015). Ensino de avaliação psicológica no Brasil: Levantamento com docentes de diferentes regiões. Avaliação Psicológica, 14(2), 253-260. Recuperado de http://pepsic.bvsalud.org/scielo. php?script $=$ sci_arttext\&pid $=$ S1677-04712015000200011

Bardin, L. (1977). Análise de conteúdo. Lisboa: Edições.

Borsa, J. C. (2016). Considerações sobre a formação e a prática em avaliação psicológica no Brasil. Temas Em Psicologia, 24(1), 131-143. doi: 10.9788/TP2016.1-09

Brasil. (1962). Lei No 4.119, de 27 de Agosto de 1962. Brasília.

Castro, P. F. (2013). Caracterização do ensino de avaliação psicológica no estado de São Paulo. Boletim de Psicologia, 63(138), 81-102. Recuperado de http://pepsic.bvsalud.org/scielo.php?script=sci_arttext\&pid=S0006-59432013000100008

CFP, Conselho Federal de Psicologia. (2003a). Resolução no 02/2003. Brasília: Conselho Federal de Psicologia.

CFP, Conselho Federal de Psicologia. (2003b). Resolução no 07/2003. Brasília: Conselho Federal de Psicologia.

CFP, Conselho Federal de Psicologia. (2010). Avaliação psicológica: Diretrizes na regulamentação da profissão. Brasília: Conselho Federal de Psicologia.

CFP, Conselho Federal de Psicologia. (2013). Cartilha avaliação psicológica. Brasília: Conselho Federal de Psicologia.

CFP, Conselho Federal de Psicologia. (2018a). Ano da formação em psicologia: revisão das diretrizes curriculares nacionais para os cursos de graduação em psicologia. São Paulo.

CFP, Conselho Federal de Psicologia (2018b). Apaf reconhece avaliação psicológica como especialidade em psicologia. Recuperado de https://site.cfp. org.br/apaf-reconhece-avaliacao-psicologica-como-especialidade-em-psicologia/

Freires, L. A., Silva Filho, J. H., Monteiro, R. P., Loureto, G. D. L., \& Gouveia, V. V. (2017). Ensino de avaliação psicológica no Norte brasileiro: analisando as ementas das disciplinas. Avaliação Psicológica, 16(2), 205-214. doi: 10.10689/AP2017.1602.11

Frizzo, N. P. (2004). Infrações éticas, formação e exercício profissional em psicologia (Dissertação de Mestrado). Universidade Federal de Santa Catarina, Florianópolis.

Hazboun, A. M., \& Alchieri, J. C. (2013). Justificativas e concepções de psicólogos que não utilizam avaliação psicológica. Avaliação Psicológica, 12(3), 361-368. Recuperado de http://pepsic.bvsalud.org/scielo.php?script=sci_arttext\&pid=S1677-04712013000300011

Hazboun, A. M., \& Alchieri, J. C. (2014). Dificuldades em avaliação psicológica segundo psicólogos brasileiros. Psico (PUCRS), 45(1), 83-89. Recuperado de http://revistaseletronicas.pucrs.br/ojs/index.php/revistapsico/article/view/13173/11444 
IBGE. (2017). IBGE divulga as estimativas populacionais dos municípios para 2017. Agência IBGE. Recuperado de https://agenciadenoticias. ibge.gov.br/agencia-noticias/2013-agencia-de-noticias/releases/16131-ibge-divulga-as-estimativas-populacionais-dos-municipiospara-2017.html

Lago, V. de M., Yates, D. B., \& Bandeira, D. R. (2016). Elaboração de documentos psicológicos: Considerações críticas à resolução CFP no 007/2003. Temas Em Psicologia, 24(2), 771-786. doi: 10.9788/TP2016.2-20

Löhr, S. S. (2011). Avaliação psicológica na formação do profissional da Psicologia: Algumas reflexões. Em Conselho Federal de Psicologia (Ed.), Ano da avaliação psicológica: Textos geradores (pp. 143-149). Brasília.

Mendes, L. S., Nakano, T. C., Silva, I. B., \& Sampaio, M. H. L. (2013). Conceitos de avaliação psicológica: Conhecimento de estudantes e profissionais. Psicologia: Ciência E Profissão, 33(2), 428-445. doi: 10.1590/S1414-98932013000200013

Noronha, A. P. P. (2006). Formação em avaliação psicológica: Uma análise das disciplinas. Interação Em Psicologia, 10(2), 245-252. doi: 10.5380/psi.v10i2.7681

Noronha, A. P. P., Carvalho, L. F., Miguel, F. K., Souza, M. S., \& Santos, M. A. (2010). Sobre o ensino de avaliação psicológica. Avaliação Psicológica, 9(1), 139-146. Recuperado de http://pepsic.bvsalud.org/scielo.php?script=sci_arttext\&pid=S1677-04712010000100015

Noronha, A. P. P., Castro, N. R., Ottati, F., Barros, M. V. de C., \& Santana, P. R. (2013). Conteúdos e metodologias de ensino de avaliação psicológica: Um estudo com professores. Paidéia, 23(54), 129-139. doi: 10.1590/1982-43272354201315

Noronha, A. P. P., Nunes, M. F. O., \& Ambiel, R. A. M. (2007). Importância e domínios de avaliação psicológica: Um estudo com alunos de psicologia. Paidéia, 37(17), 231-244. doi: 10.1590/S0103-863X2007000200007

Noronha, A. P. P., Ziviani, C., Hutz, C. S., Bandeira, D. R., Custódio, E. M., Alves, I. B., ... Domingues, S. (2002). Em defesa da avaliação psicológica. Avaliação Psicológica, 1(2), 173-174. Recuperado de http://pepsic.bvsalud.org/scielo.php?script=sci_arttext\&pid $=$ S1677-04712002000200010

Nunes, M. F. O., Muniz, M., Reppold, C. T., Faiad, C., Bueno, J. M. H., \& Noronha, A. P. P. (2012). Diretrizes para o ensino da avaliação psicológica. Avaliação Psicológica, 11(2), 309-316. Recuperado de http://pepsic.bvsalud.org/scielo.php?script=sci_arttext\&pid $=$ S1677-04712012000200016

Paula, A. V., Pereira, A. S., \& Nascimento, E. (2007). Opinião de alunos de psicologia sobre o ensino em avaliação psicológica. Psico-USF, 12(1), 33-43. Recuperado de http://pepsic.bvsalud.org/scielo.php?script=sci_arttext\&pid=S1413-82712007000100005

Preto, C. R. de S., \& Fajardo, R. S. (2015). Laudo psicológico no Brasil: Revisão de literatura com foco em estruturação e conteúdo. Arch Health Invest, 2(4), 40-52. Recuperado de http://www.archhealthinvestigation.com.br/ArcHI/article/view/888

Rafalski, J. C., \& Andrade, A. L. (2015). Prática e formação: Psicólogos na peritagem em porte de arma de fogo. Psicologia: Ciência E Profissão, 35(2), 599-612. doi: 10.1590/1982-370301472013

Shine, S. K. (2009). Andando no fio da navalha: Riscos e armadilhas na confecção de laudos psicológicos para a justiça (Tese de doutorado). Universidade de São Paulo, São Paulo.

Urbina, S. (2007). Fundamentos da testagem psicológica. Porto Alegre: Artmed.

\section{Sobre os autores}

Rodolfo A. M. Ambiel é psicólogo, Doutor em Psicologia pela Universidade São Francisco (USF). Docente de graduação e do Programa de Pós-graduação Stricto Sensu em Psicologia da Universidade São Francisco. É editor-chefe da Revista Psico-USF (Qualis A2). Presidente da Associação Brasileira de Orientação Profissional (ABOP) - gestões 2015-2017 e 2017-2019. Bolsista Produtividade do CNPq - nível 2.

Ana Carolina Zuanazzi é psicóloga (UEL), Mestre em psicologia clínica (USP) e doutoranda em psicologia, com ênfase em Avaliação Psicológica, pela Universidade São Francisco (USF). Membro do Laboratório de Saúde Mental (LaPSaM). Membro do corpo editorial da Revista Psico-USF (Qualis A2).

Catarina Possenti Sette é psicóloga, Doutora em Psicologia, com ênfase em Avaliação Psicológica, pela Universidade São Francisco (USF). Parte do corpo editorial da Revista Psico-USF (Qualis A2). Dirige seus estudos com foco em transtornos da personalidade, traços patológicos da personalidade, redes sociais e dependência de tecnologias.

Ariela Raissa Lima Costa é psicóloga (UESPI), mestre e doutoranda em Psicologia, com ênfase em Avaliação Psicológica, pela Universidade São Francisco (USF).

Felipe Augusto Cunha é psicólogo, mestre e doutorando em Psicologia, com ênfase em Avaliação Psicológica, pela Universidade São Francisco (USF). 